\title{
MicroMechanical Characterization Tools for Highly-Filled Polymers
}

S. Groves, S. DeTeresa, B. Cunningham, D. Ciarlo, D. Allen, K. Clayton, C. Yoon

February 16, 2000

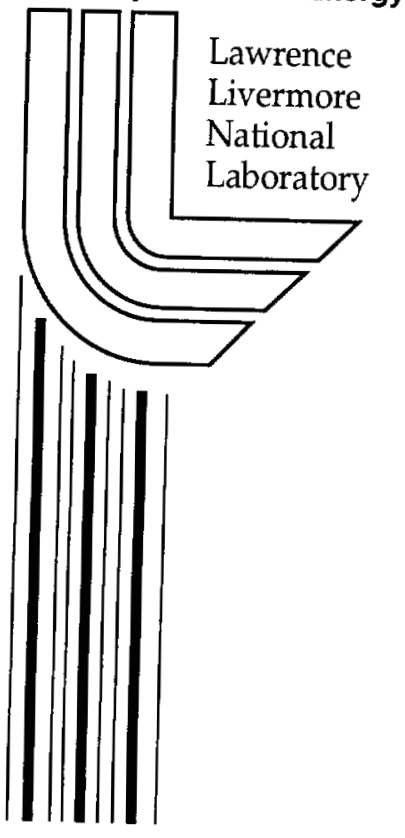




\section{DISCLAIMER}

This document was prepared as an account of work sponsored by an agency of the United States Government. Neither the United States Government nor the University of California nor any of their employees, makes any warranty, express or implied, or assumes any legal liability or responsibility for the accuracy, completeness, or usefulness of any information, apparatus, product, or process disclosed, or represents that its use would not infringe privately owned rights. Reference herein to any specific commercial product, process, or service by trade name, trademark, manufacturer, or otherwise, does not necessarily constitute or imply its endorsement, recommendation, or favoring by the United States Government or the University of California. The views and opinions of authors expressed herein do not necessarily state or reflect those of the United States Government or the University of California, and shall not be used for advertising or product endorsement purposes.

This work was performed under the auspices of the U. S. Department of Energy by the University of California, Lawrence Livermore National Laboratory under Contract No. W-7405-Eng-48.

This report has been reproduced directly from the best available copy.

Available electronically at http://www.doc.gov/bridge

Available for a processing fee to U.S. Department of Energy

And its contractors in paper from

U.S. Department of Energy

Office of Scientific and Technical Information

P.O. Box 62

Oak Ridge, TN 37831-0062

Telephone: (865) 576-8401

Facsimile: (865) 576-5728

E-mail: reports@adonis.osti.gov

Available for the sale to the public from

U.S. Department of Commerce

National Technical Information Service

5285 Port Royal Road

Springfield, VA 22161

Telephone: (800) 553-6847

Facsimile: (703) 605-6900

E-mail: orders@ntis.fedworld.gov

Online ordering: http://www.ntis.gov/ordering.htm

\section{OR}

Lawrence Livermore National Laboratory

Technical Information Department's Digital Library

http://www.llnl.gov/tid/Library.html 


\title{
MicroMechanical Characterization Tools for Highly-Filled Polymers
}

\author{
Scott Groves, Steve DeTeresa, Bruce Cunningham, and Dino Ciarlo \\ Lawrence Livermore National Laboratory \\ David Allen, K. Clayton, and C. Yoon \\ Texas A\&M University
}

FY99 Engineering LDRD Annual Report

\begin{abstract}
We are attempting to characterize and model the micromechanical response of highly-filled polymers. In this class of materials, the continuous plastic binder used to bond the highly-filled material dominates the observed viscoelastic response. As a result, realistic lifetime analysis of these materials will require a thorough understanding of the contribution of the plastic binder.

Laboratory applications of these materials include plastic bonded explosives, propellants, a variety of specialized filled organic materials for stockpile systems, and highly filled epoxy dielectric materials for the National Ignition Facility.

We have explored numerous techniques to characterize the local microstructure of plastic bonded explosives. However, insufficient funding was obtained to bring these technologies to maturity, nevertheless our present tool set is significantly better than 2 years ago.

We have also made some progress in developing an appropriate micromechanical constitutive modeling framework, based on a finite element method incorporating a cohesive zone model to represent the binder contribution within a Voronoi tesselation mesh structure for the PBX grains. A second modeling approach was used to incorporate analytical micromechanics (generalized self-consistent schemes). However, preliminary theoretical analysis strongly suggested that this approach would be invalid for such extremely high-filled systems like PBX.
\end{abstract}




\section{Introduction}

The mechanical properties of highly-filled polymers (HFPs) are generally dominated by the properties of the binder, because the binder is still a continuous phase, even at low concentrations. An example of this effect is shown in Figure 1. Here, the mechanical properties of a representative plastic bonded explosive (PBX) is shown to be highly dependent on relatively small changes in temperature. This particular system is composed of $95 \%$ high explosive (HE) crystals and 5\% binder. Over the temperature range shwon, the HE crystals experience no significant change in properties, whereas, the binder experiences significant mechanical property changes. This is in large part because the binder has a glass transition temperature that falls within the range of operation.

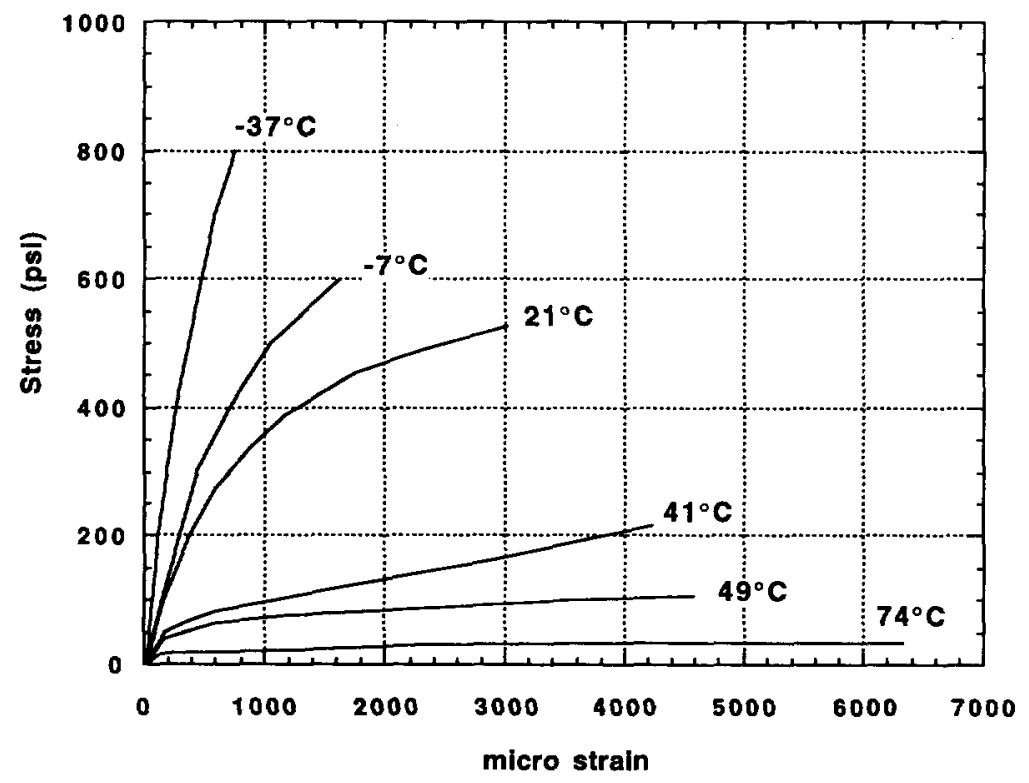

Figure 1. Temperature dependence of tensile properties of PBX-LX14.

In general, HFPs are highly time-dependent and non-linear, with typical applications at LLNL requiring $30+$ years of expected service. Long-term modeling will require accurate thermo-viscoelastic/plastic material models with the ability to capture microstructural / in situ properties of the constituents. Developing material models that can relate constituent properties to macroscopic composite properties have considerable benefits, especially in the case of energetic materials. Characterizing the polymer binder independently is simpler and with PBX, poses no safety concern. These tools would also facilitate the incorporation in models of any identifiable chemical or physical aging mechanisms, thus, forming a solid foundation for conducting accelerated aging studies on these materials. Furthermore, this suite of tools and models will enhance the prediction of the mechanical response of new HFP formulations, which in turn, could reduce the qualification time for the replacement of material components. 
This paper will discuss our efforts to characterize the local microstructure, to measure in-situ properties of the local volume, to measure binder constituent properties, and to perform micromechanical modeling.

\section{Microscopic Characterization of the Local Volume}

This task is associated with developing tools for determining the local microstructure of highly filled polymers. In extremely high-volume filled polymers like PBX, it has been difficult to distinguish the location of the binder phase. Traditional surface microscopy has not been very useful. The example shown in Figure 2 represents a LANL-developed polarized light microscopy image of a very thin wafer of PBX (which required considerable effort to produce).

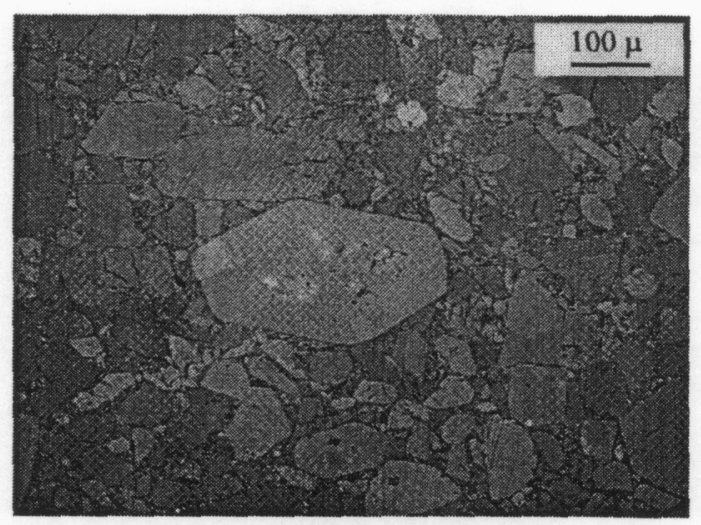

Figure 2. Polarized light microscopy image for PBX from LANL.

Micro computed x-ray tomography has been explored, but proved to lack the resolution necessary to clearly identify the binder. The best resolutions available are $3-5 \mu \mathrm{m}$, which falls short of the requirement by better than an order of magnitude.

Atomic Force Microscopy was also explored, but suffered from having incompatible tip designs for probing and identifying soft binder between the grains of high explosive.

In order to improve our ability to characterize the local microstructure of PBX, this project applied the majority of its funding to purchase a new type of Scanning Electron Microscope (SEM) that can image organic based materials without the need to apply a thin layer of conductive coating such as gold. With regard to coating, our concern has been that the conductive coating would mask some of the microstructural features of interest. The SEM purchased was a LEO 438 Variable Pressure System, see Figure 3. LEO is the new name of Cambridge Instruments (developer of the first commercial SEM). This facility has only recently been approved for high explosive work. Some of the images that we have obtained with this system are shown in Figure 4 

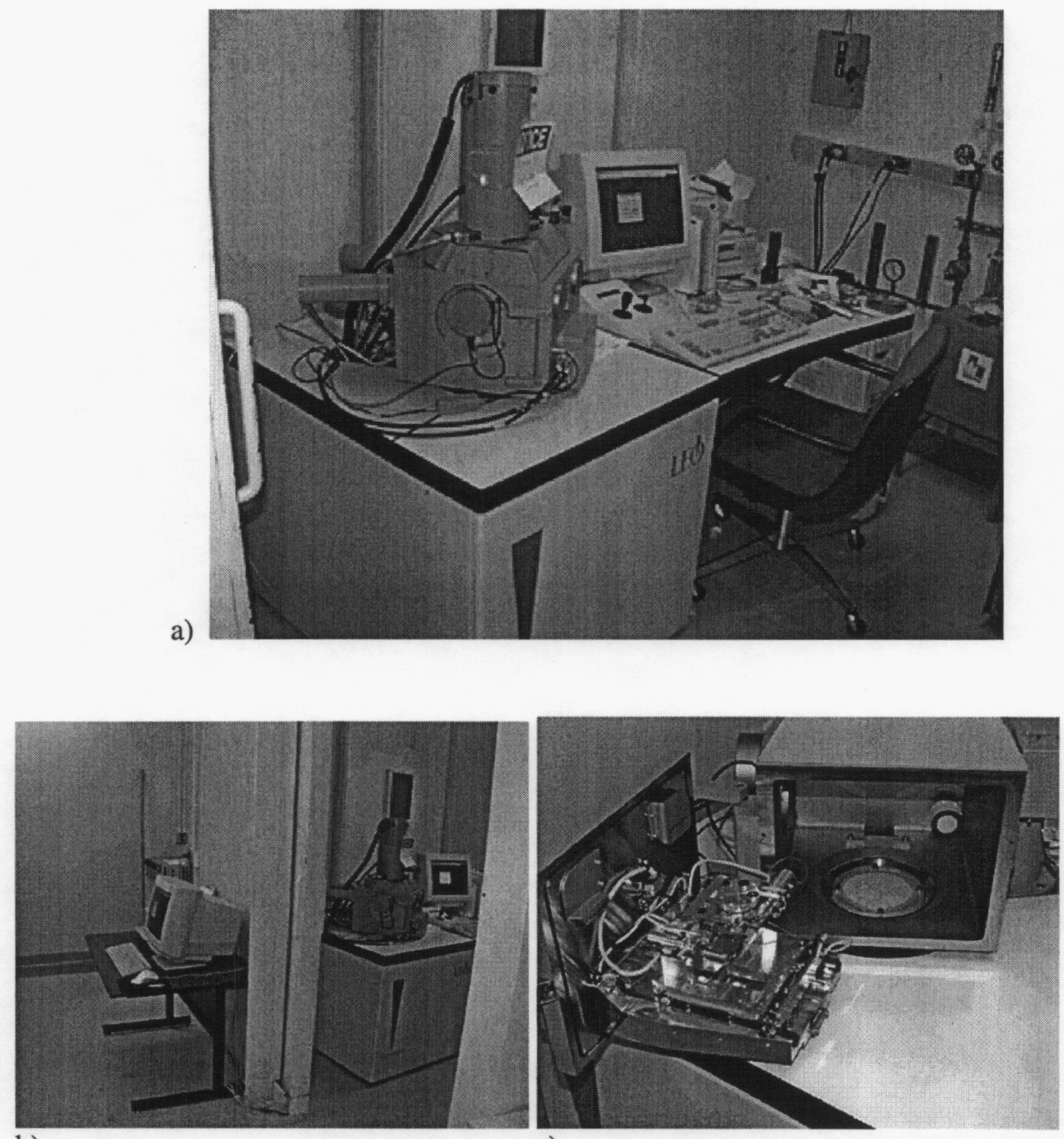

b)

c)

Figure 3. a) LEO 438 Variable Pressure Scanning Electron Microscope located in building 191 HEAF, room 1500, b) configured in remote operation for high explosives, c) scanning chamber open revealing high explosive filters on turbo pump. 


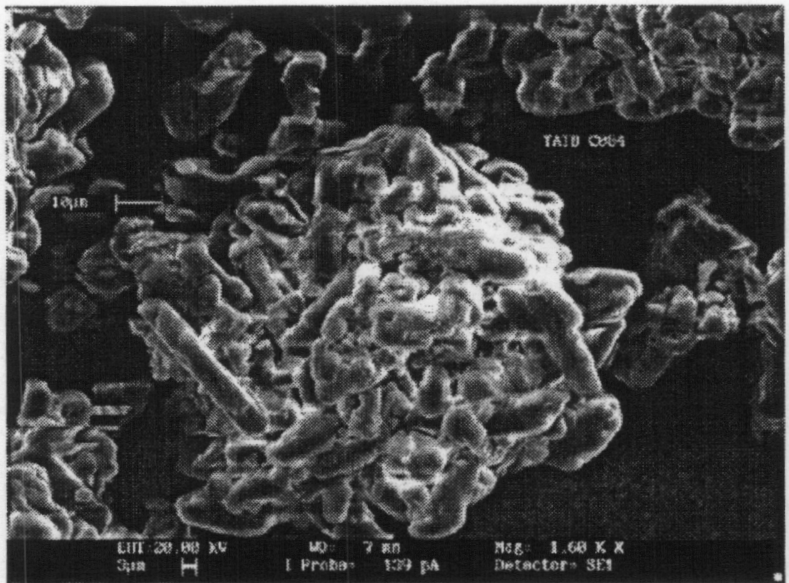

a) clustures of TATB particles

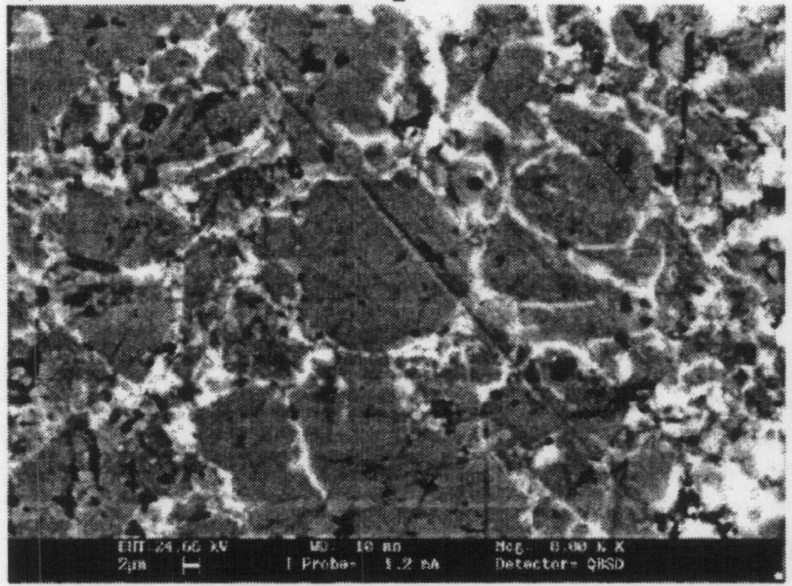

c) LX17-1 polished surface.

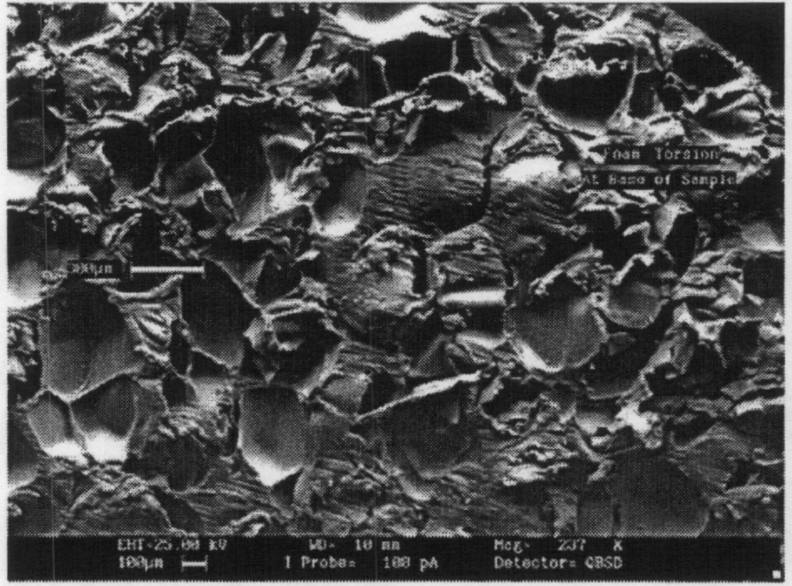

e) torsion failure surface of foam.

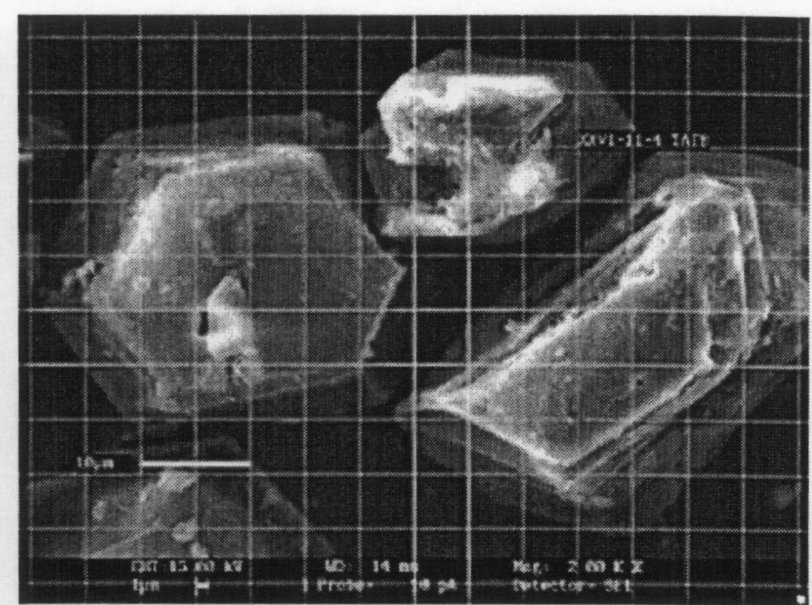

b) individual TATB particles

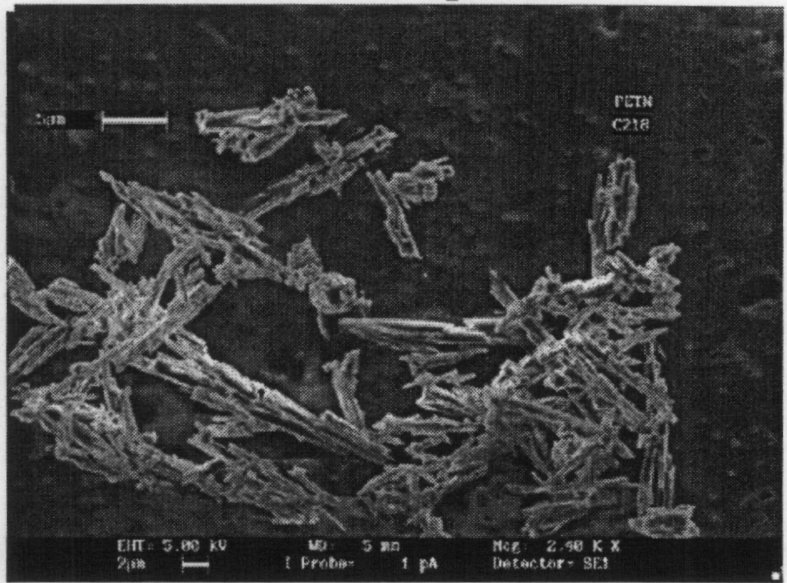

d) PETN particles used in detonators.

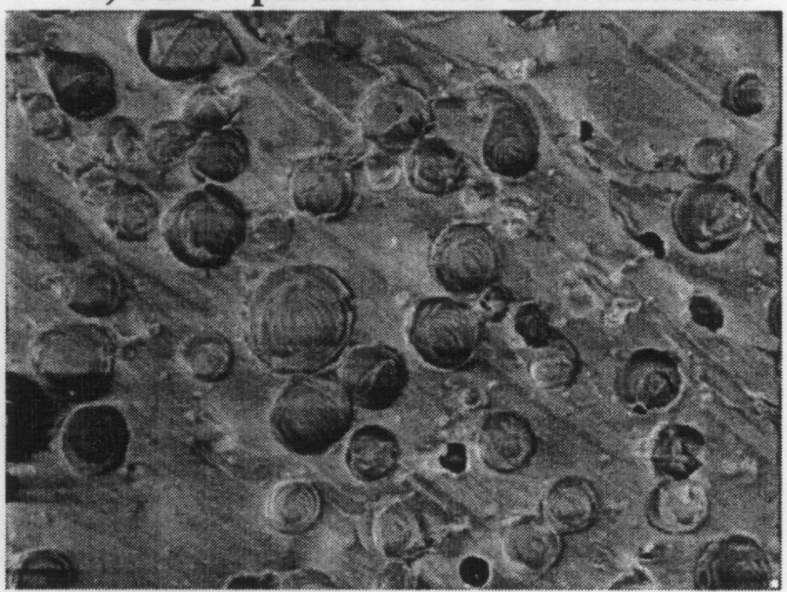

f) a filled foam.

Figure 4. SEM images obtained with the new LEO 438 VP. Note, all of the pictures shown were obtained without conductive coatings. Figure 4c) represents our first attempt at imaging a polish surface of LX17. This surface was hand lapped in an ice water bath to improve KELF polishing. We believe that the lighter colored material is the KELF binder. It appears light in this image due to electron charging. 
To further enhance our imaging capabilities we have begun to explore the use of stereo image capture and rerendering within the SEM. Modern software and tools developed for the computer gaming industry has made it very user friendly within the PC environment. Our preliminary work with 3D imaging on filled organics and mock explosives reveals significantly greater depth of field information.

We also intend to explore tagging the binder with a stain or a higher density element during processing in order to enhance its contrast relative to the filler.

\section{In-situ Property Characterization}

A relatively new technique, "Atomic-Force Microscopy with Nano-Indentation" was explored to investigate the in-situ response (that is, to measure force deflection behavior) on mock HE. It became quickly apparent that current probe designs are grossly inadequate to determine the required in-situ properties. What is needed is to reduce the size of the probe diameter while at the same time increasing the probe length. Concurrently, we must also reduce applied forces from micro Newtons to nano Newtons.

An effort was initiated to develop our own nano indentation system around a newly designed, high aspect ratio probe tip. Hardware was purchased for what was expected to be our base system foundation, including three stages of nano-meter motion control as well as hardware to develop a stereo microscopic viewing system for positioning the nano indentation probe on the material.

Initially, we planned to measure the viscoelastic properties of the binder material in its position surrounding the HE. To do this, a special probe was needed to apply a constant force on the binder material and measure the displacement as a function of time. It is expected that the material will yield plastically as well as creep. We will also apply a constant strain to the material and monitor the relaxation in force required to maintain this strain. The forces, displacements, and time constants resulting from these measurements will be used in developing micromechanics models.

Insufficient funding was secured to continue much of this work under the LDRD Nevertheless some progress has been made in the development of the tool set. In some sense, commercial technology has passed us by, with the newly availabile nano indentation systems.

Tech Base funding from the MicroTechnology Center was obtained to continue development of the high aspect ratio tip. For our applications, we need a probe with a circular contact area having a diameter of $0.1 \mu \mathrm{m}$ and a shaft length of $2 \mu \mathrm{m}$. Silicon micromachining was used to fabricate this probe. The tip has a radius of $\sim 1.5$ nano meters. Just recently this new nano tip was installed in a traditional AFM. Our recent scans on mock HE have been very encouraging, with the results shown in Figure 5. In these results, color is used to denote surface height.

Additional progress has included demonstration of stereo microscopic imaging tools, as well as development of a baseline labview control system for the nano mover stages. 


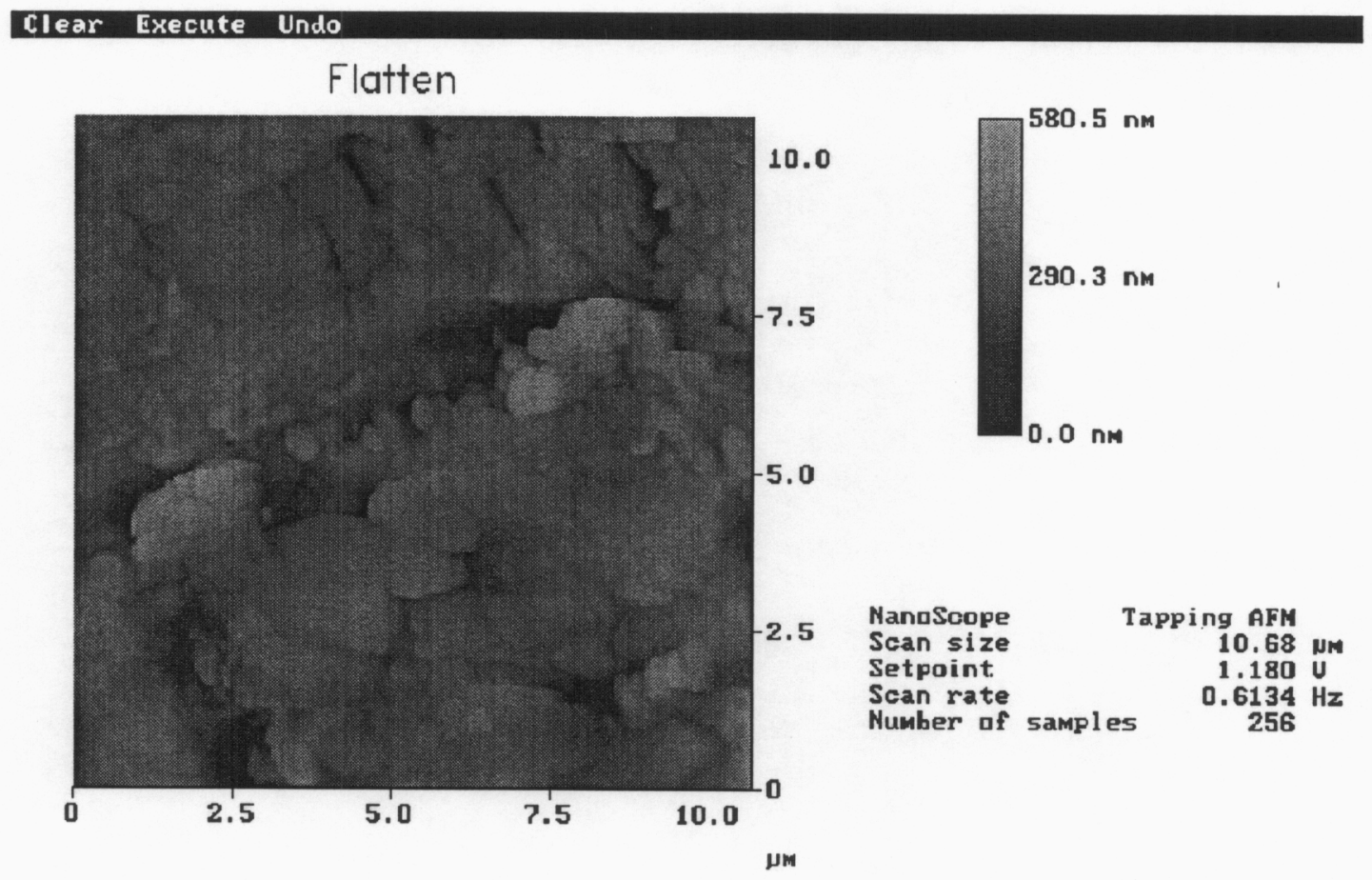

oldtpx, 006

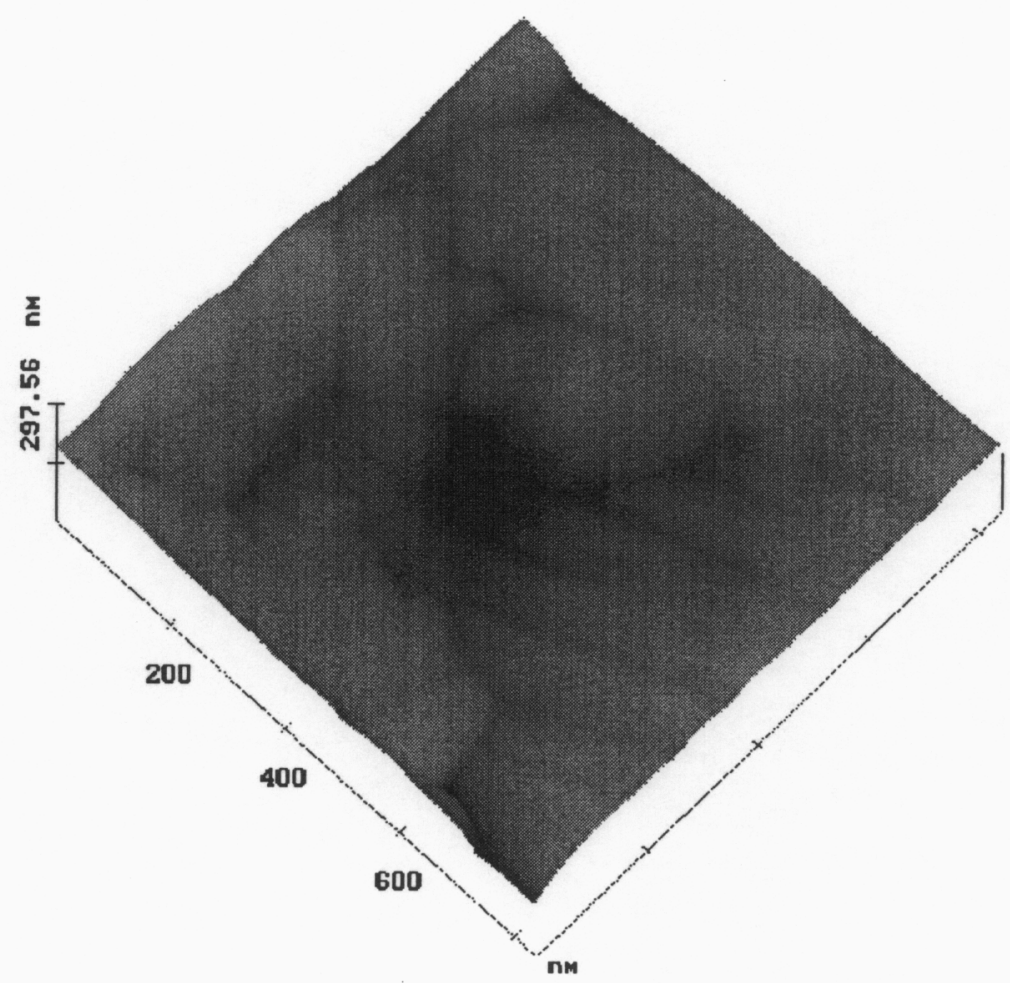

Figure 5. Atomic Force Microscope scans using the recently developed nano-tip probe. 


\section{Characterization of Binder Constituent Properties}

The objective of this task was to determine the mechanical properties of the individual constituents for the selected material systems. For the case of PBX, our focus was on characterizing the response of the KELF binder used in LX17. Other groups are attempting to characterize the elastic properties of the explosive crystals. Characterizing the mechanical response of binders is not a trivial task. These materials are very soft and require self-supporting grips to prevent premature deformation or bending of the specimen. Furthermore, since the glass transition temperature is spanned by the operating temperature of this system, temperature control during testing is very critical. This has required the installation of water bath temperature controls for maintaining temperature stability, especially at any temperatures near and below $22^{\circ} \mathrm{C}$.

A suite of thermal creep data has been generated on the KELF binder. These results are shown in Figures 6 and 7. This data was converted into compliance data as shown in Figure 8.

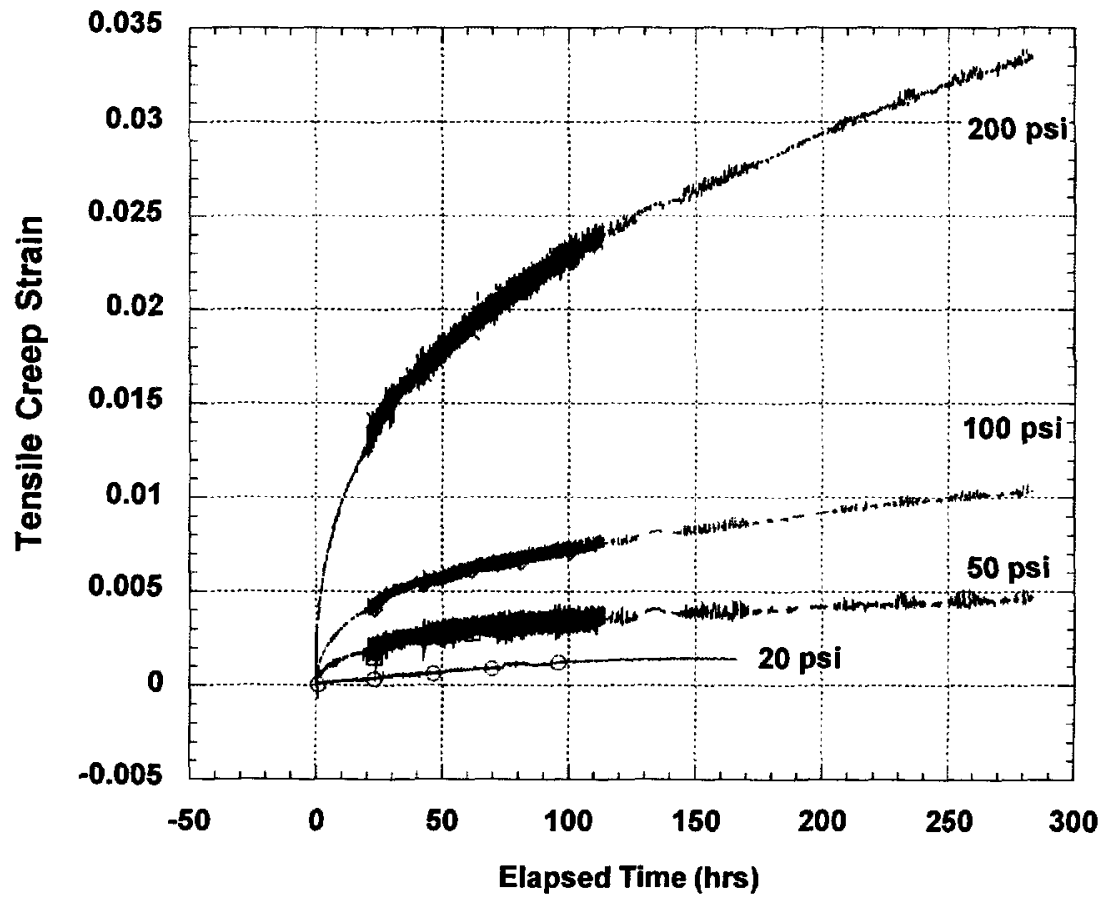

Figure 6. KELF binder tensile creep at $15^{\circ} \mathrm{C}$ temperature. 


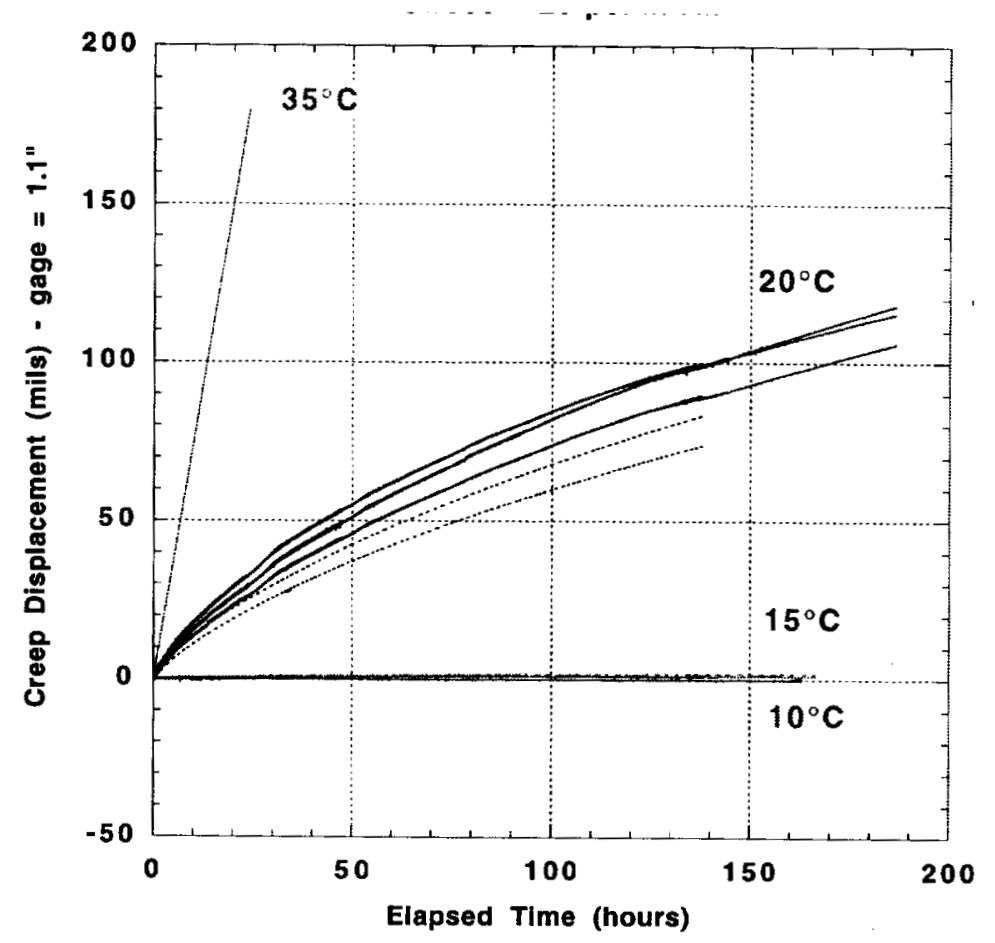

Figure 7. Variation in the thermal tensile creep response of KELF at 20 psi .

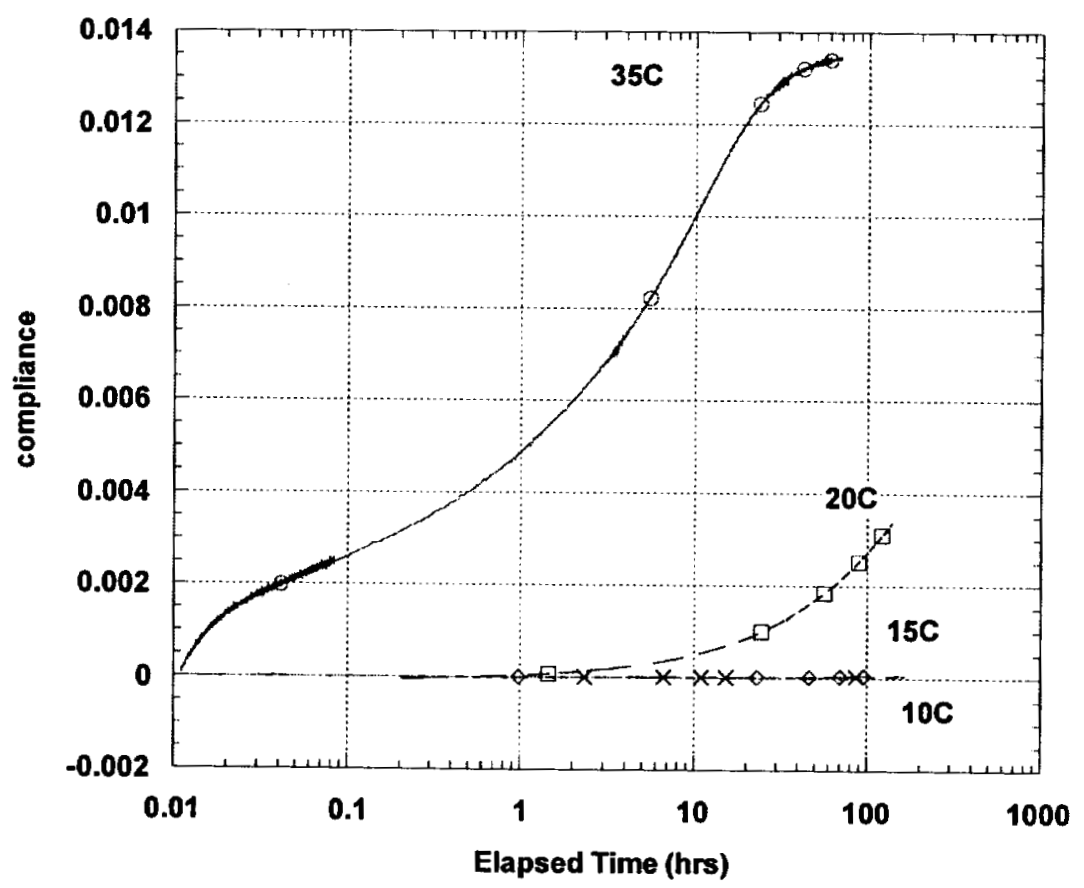

Figure 8. KELF creep compliance data. 
For use in finite element material modeling codes, compliance data must be recast into relaxation modulus data using the following inversely proportional relationship:

$$
\widetilde{E}(s)=\frac{1}{\widetilde{D}(s)}
$$

where $D(s)$ is the creep compliance in Laplace space, $E(s)$ is the relaxation modulus in Laplace space, and the $\sim$ indicates the Carson transform. The inverse Laplace transform (I.L.T.) was taken of $E(s)$ in order to get the relaxation modulus as a function of time. The I.L.T. was performed two different ways - analytically and using Schapery's Direct method [1]. The different curve fits and different I.L.T. methods were utilized in order to make comparisons and thereby decide which method would be the best. The predicted relaxation moduli are shown in Figure 9.

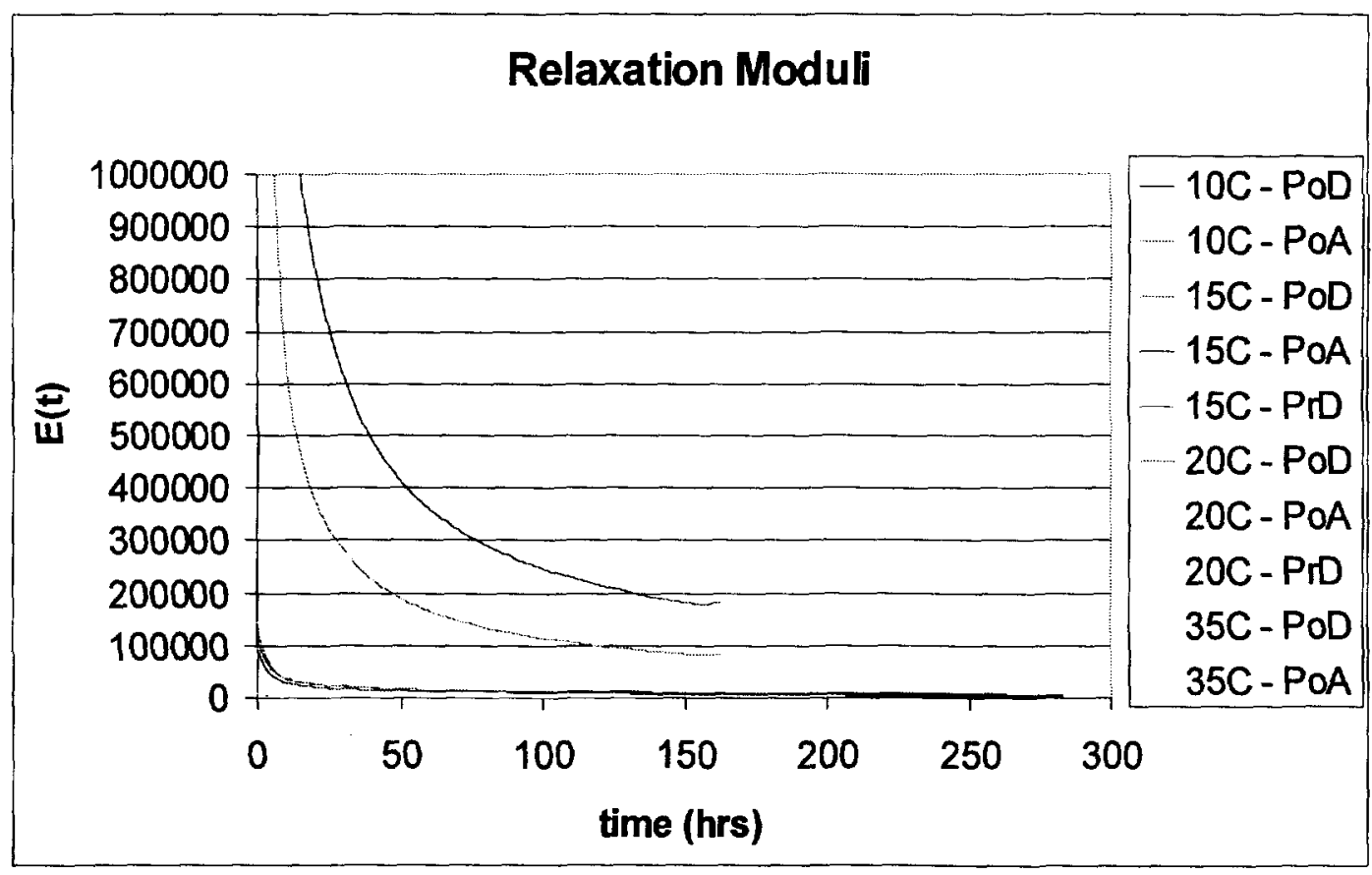

Figure 9. Predicted relaxation moduli for KELF binder.

Since the values of the relaxation moduli at the different temperatures differ so greatly, the higher temperatures do not show up well on Figure 10. However, this graph shows the potential for making the master curve of the binder. By using a shift factor and a time scaling factor for the relaxation moduli at different temperatures, the master curve can be obtained for the binder. The shift factor is typically calculated using different methods for above and below the glass transition temperature $\left(\mathrm{T}_{\mathrm{g}}\right)[2,3]$. Below $\mathrm{T}_{\mathrm{g}}$, the Arrhenius relation can often be used: $\log a_{T}=\frac{\Delta F}{2.303 R}\left(\frac{1}{T}-\frac{1}{T_{M}}\right)$ 
where $a_{T}$ is the shift factor, $\Delta \mathrm{F}$ is a constant activation energy per gram mole when $\mathrm{R}=1.987$ (cal/g-mole ${ }^{\circ} \mathrm{K}$ ) and $\mathrm{T}_{\mathrm{M}}$ is the reference temperature. Above $\mathrm{T}_{\mathrm{g}}$, the WLF form is often used:

$\log a_{T}=\frac{-C_{1}\left(T-T_{M}\right)}{C_{2}+T-T_{M}}$

where $C_{1}$ and $C_{2}$ are constants. $T_{g}$ of this material is around $25 C$, so all except the $35 \mathrm{C}$ data will be shifted using the Arrhenius form.

These transformations are made in order to model the thermorheologically simple thermoviscoelastic material properties of the PBX

\section{Micromechanical Modeling}

In our micromechanical modeling effort we are assessing the merits of two different approaches: analytical micromechanics (a composite spheres model) and finite element analysis. Common in all methods is the desire to develop a representative local volume element of material. Theoretical analysis of the former analytical approach suggests that method would be inappropriate for modeling extremely highly-filled systems like PBX. The discussion of this is given below.

\section{Inefficiency of Analytical Micromechanics (Composite Sphere Model) for Material System with Inclusions of High Volume Concentration}

A very small or large volume concentration formula for heterogeneous material can be validly obtained from the analytic solutions of classical micromechanics by truncating the higher order terms of volume fraction of the inclusion or that of matrix. However, it has been assumed in the theoretical micromechanics analysis that the contact length between particles (called 'contiguity') is always zero for all concentrations, no matter what the configuration of the inclusion is. Clearly, this assumption cannot be expected to hold for the case of PBX. Below is a citation from a well known work in the field of theoretical micromechanics;

\footnotetext{
"A fundamental assumption made in this work is that of zero contiguity. Obviously, this cannot be true for a real material. The contiguity is an increasing function of the fractional volume of inclusions and can be expected to be very small only in the case of small concentration. When the concentration is close to unity it would appear more reasonable to assign the role of matrix to the inclusion material and that of inclusions to the matrix." [4]
}

The suggestion about switching the roles of inclusions and matrix does not seem to be reasonable even when no damage is introduced, since the inclusions (explosive particles) have elastic material behavior whereas the binder material (matrix) behaves viscoelastically. Once damage evolves and cracks propagate in the matrix, this proposed role reversal continues to be unrealistic. 
Aside from the contiguity problem, there are other difficulties in using analytic estimation to obtain the effective moduli. It is commonly believed that whenever the difference in moduli between inclusions and matrix materials is not too large, the upper and lower bounds will be close together. However, in such an extreme case as PBX, the bounds are not close enough to provide a good estimation of an effective moduli of the composite.

Analytic theory has another discrepancy. The composite spheres model cannot account for the size deviation effect and irregular shape effect that play critical roles in estimating the effective material properties. Inclusion particle sizes in PBX show large scatter. In addition, it has been shown that the inclusion particles in PBX have various irregular shapes and most of them are of sharp configuration. Wherever the explosive particles have sharp corners or acute angled edges, a stress concentration is expected. These stress concentrations will make damage evolve in the binder material, and the damage evolution consequently leads to more stress concentrations. With the composite spheres model these effects are not accounted for, so that the subsequent prediction of damage evolution will necessarily be erroneous. For these reasons, finite element methods are being studied in this research with the expectation that they will better predict damage dependent, effectively averaged properties for PBX.

\section{Finite Element Approach}

In our finite element material modeling effort we are utilizing Voronoi tessellation mesh structures $[5,6,7]$ to simulate the distribution of the highly-filled component and a cohesive zone model $[8,9]$ between each component. The fundamental idea in this approach is to reduce the effects of the extremely low volume material to that of a line function in the finite element mesh, thus avoiding the tremendous memory penalty for modeling both grains and binder. The later method of modeling both grains and binder from a pure continuum sense within the finite element algorithm will be explored in the future. It is essential to have correct material properties for the line function. (This approach might be considered similar to having a tied slide line, as in NIKE, except the line will have constitutive properties). The advantage of the cohesive zone model, which contain double nodes at each point, is in the facilitation of simulated damage (fracture between the grains) in our representative local volume. Homoginization of the boundary response (with or without damage) leads to a set of representative properties.

For our particular case the highly-filled component is the explosive grains, and the low concentration material is the viscoelastic binder, KELF.

Two meshes, shown in Figures 10, will initially be used to model the material. They are double noded meshes with 30 grains and 100 grains, respectively. Since the material has such a high volume fraction $(\sim 92 \%)$, a refined mesh with a finite space between grains is difficult to generate. Therefore we are using these meshes with a cohesive zone model and zero opening dimension in the undeformed configuration along the grain boundaries to model the binder. The relaxation moduli obtained through the method described previously are fitted using a Prony series that is used in the cohesive zone model. The characteristic length scale of the cohesive zone and the Young's modulus of the particles (grains) are still unknown but are necessary if we hope to achieve an accuracy in our finite element models. Preliminary properties for the elastic 
behavior of the explosive grains will have to be initially estimated by backing them out from measured PBX global properties.

a)

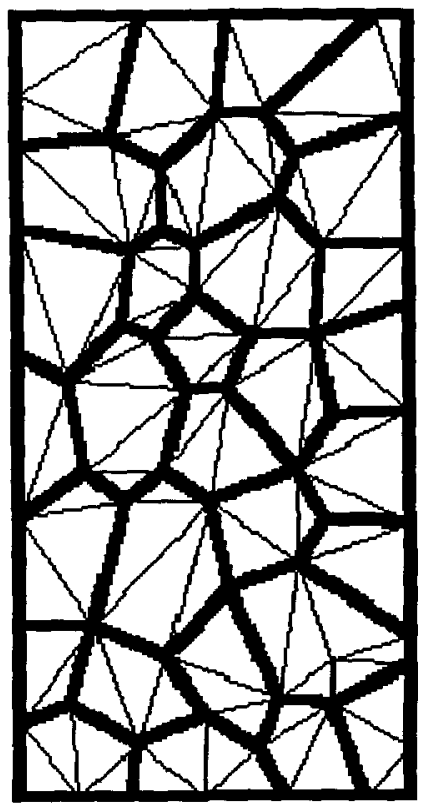

b)

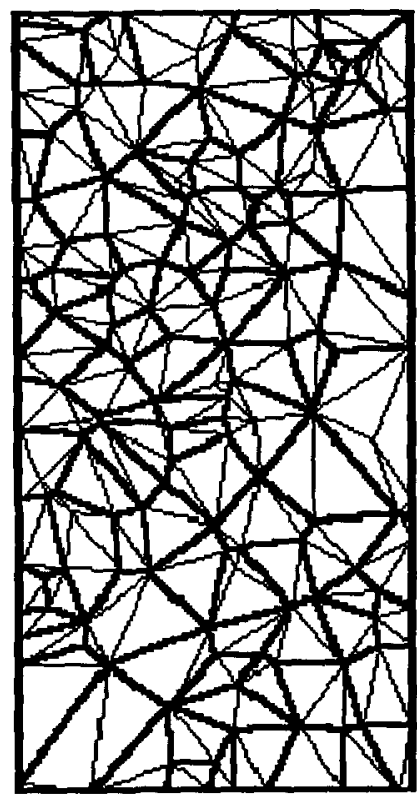

Figure 10. Preliminary Voronoi finite element mesh structures for PBX. Mesh a) is a 30 grain and 97 element model. Mesh b) is a 100 grain and 292 element model. One of our goals is to determine the convergence of mesh refinement.

\section{Summary}

This project has served to further the development of those tools necessary to characterize highly-filled polymers. When further developed and linked together with the viscoelastic modeling tools, this methodology will provide a basis for estimating the useful lifetime and identifying any age-related problems for these materials.

\section{References}

1. R. A. Schapery,"Stress Analysis of Viscoelastic Composite Materials," Journal of Composite Materials, vol. 1, pp 228-267 91967)

2. Struik, L.C.E.," Physcial Aging in Amorphous Polymers and Other Materials, Eksevier Scientific Publishing Co., 1978.

3. Christensen, R.M., "Theory of Viscoelasticity, Academic Press, 1971.

4. Zvi Hashin, "The Elastic Moduli of Heterogeneous Materials", Journal of Applied Mechanics, 1962, pp.143-150. 
5. Rodin, G.J. "Stress Transmission in Polycrystals with Frictionless Grain Boundaries," Journal of Applied Mechanics, March 1995, Vol. 61/2.

6. Van Der Burg, M.W.D, and Van Der Giessen , E. " Delaunay-Network Modelling of Creep Failure in Regular Polycrystalline Aggregates by Grain Boundary Cavitaion," International Journal of Damage, vol. 3, April 1994.

7. Starzewski, M. O. and Wang. C., "Linear Elasticity of Planar Deluanay Networks: Random Field Characterizationi of Effective Moduli," Acta Mechancia, 80, 61-80, 1989.

8. Yoon, C. and Allen, D.H.,"Damage Dependent Constitutive Behavior and Energy Release Rate for a Cohesive Zone in a ThermoViscoelastic Solid," submitted to International Journal of Fracutre.

9. Costanzo, F. and Allen, D.H., "A Continuum Mechanics Approach to Some Problems in Subcritical Crack Propagation," International Journal of Fracture, 63, 27-57, 1993. 